\title{
Modelling and numerical simulation of fire in a coffee storage hall
}

\author{
Kalin Krumov ${ }^{1}$, Nina Penkova $^{1 *}$, Boian Mladenov ${ }^{1}$, and Yordan Stoyanov ${ }^{1}$ \\ ${ }^{1}$ University of Chemical Technology and Metallurgy, Department of Silicate Technology, Blvd. Sv. \\ Kliment Ohridski 8, 1756 Sofia, Bulgaria
}

\begin{abstract}
An approach for modelling of fire in halls at solid materials burning, based on gas phase combustion models in ANSYS/CFX, is proposed. The models are suitable for quick prediction of the flue gases distribution and thermal loads on the building envelopes at a design stage. They was applied for numerical simulation of such processes in a coffee storage hall at different fire positions and forced anti-smoke ventilation. The thermal, fluid flow and concentration field were obtained at the modelled scenarios. Maximal thermal loads on the building envelopes are established at the case of fire near their non-streamlined parts.
\end{abstract}

\section{Introduction}

The prediction of smoke and heat distribution at the cases of fire is important for the sizing and mounting of the building components and materials, smoke vents, sprinkler and ventilation systems [1]. The modeling and computer simulation are convenient ways for analysis of possible burning processes in the buildings [2,3,4]. Different CFD techniques are used for fire modeling: Direct Numerical Simulation (DNS), Large Eddy Simulation (LES) and Reynolds-Averaged Navier-Stokes (RANS) [2].

DNS requires very fine spatial and temporal resolutions (about $1 \mathrm{~mm}$ or less). It is convenient for low Reynolds number flows and simple geometries and is not practical for large-scale fire simulations. LES is suitable for "large eddies" modeling at relatively coarse space meshes. It is the base of the computational code Fire Dynamics Simulator (FDS), widely used for fire analysis at large-scale buildings [1, $5-7]$. The software allows numerical simulations of low-Mach flows, driven by the released combustion heat and the buoyancy via the coupled LES, combustion and radiation models [8].

The CFD techniques, based on RANS also allow solutions of combustion models by finite volumes method. Such models for gaseous and liquid fuels are well developed and proved [9]. However, the computational models of solid material burning at fire are still in the process of development, validation and verification.

The aim of the present study is to develop and test a model for quick numerical simulation of fires in buildings at burning of solid materials, based on RANS and gas phase combustion models, available in ANSYS. An idea for such modeling is mention in [10]. Here it is

* Corresponding author: nina@uctm.edu 
developed in details for numerical simulation of released smoke and heat at burning of coffee in a storage hall.

\section{Modeling of fire in buildings at burning of solid materials}

The models bellow allow numerical simulation of quasi-stationary fire at moments of the unsteady burning. They are based on the idea for a modeling of the burning of solid materials by gas fuel combustion at the same released heat and smoke flows. The possible fire locations are modeled as sources of gas mixture, containing combustible and noncombustible components: methane, carbon monoxide, hydrogen sulfide and water vapor. The mass fractions of these components and the gas mass flow are computed in order to release equal emissions as at the solid burning:

- heat flows and heat release rate;

- mass flows of the products of the reactions $\mathrm{CO}_{2}, \mathrm{SO}_{2}$ and $\mathrm{H}_{2} \mathrm{O}$.

The first acceptance is not new. It is the base of the so-called Pyrolysis model of FDS: the mass flow of a chosen in advance hydrocarbon gas fuel is computed and applied on the "burning area" at known heat release rate of the burning solid materials [8].

That approach allows numerical simulation of fire at solid material burning with RANS based software as CFX (ANSYS), using the available gas phase combustion models for the computations of the correspondent mixing and chemical reactions. The radiation heat transfer at solid materials burning can be modeled via calibration of the radiation model in order to ensure equal flame emissivity for the both types of fuels. The formation, moving and dissipations of the eddies are represented by the turbulent viscosity, kinetic energy and energy dissipation rate, computed by turbulence models. The finer meshes and the smaller real and physical time steps allow obtaining of sufficiently accurate information for the distribution of the released flue gases and heat in the building space at a case of fire.

A three-dimensional geometrical model of the internal space of the hall is generated. The doors, windows, smoke vents and the possible fire locations present in the model as merged surfaces on the walls. Different scenario of fire can be simulated moving the fire locations in the geometrical model. The internal building space is discretized by a mesh of finite volumes in order to solve numerically the system of partial differential equations:

- continuity equation;

- $\quad$ momentum equations at non zero gravity to model the buoyancy;

- $\quad$ thermal energy equation;

- $\quad$ k- $\varepsilon$ or k- $\omega$ turbulence model;

- $\quad$ gas phase combustion model;

- $\quad$ radiation model.

The air, gas fuel mixture and the product of the reactions are accepted as ideal gases: their density are computed by the corresponding equations of the state. Possible boundary conditions are summarized in Table 1.

Table 1. Boundary conditions.

\begin{tabular}{|c|c|}
\hline Boundary & Variable \\
\hline Fire locations (inlets) & $\begin{array}{c}\text { Gas mixture mass flow, mass fractions of the } \\
\text { components, gas temperature. }\end{array}$ \\
\hline $\begin{array}{c}\text { Vertical opened windows and doors } \\
\text { (opening boundaries) }\end{array}$ & $\begin{array}{c}\text { Wind pressures with positive values at the windward } \\
\text { facades and negative on the leeward ones, the ambient } \\
\text { temperature. }\end{array}$ \\
\hline $\begin{array}{c}\text { Openings for forced air supply in a } \\
\text { case of fire (inlets) }\end{array}$ & $\begin{array}{c}\text { Average velocity or mass flow of the airflow, } \\
\text { temperature. }\end{array}$ \\
\hline
\end{tabular}




\begin{tabular}{|l|c|}
\hline $\begin{array}{c}\text { Smoke vents on the roofs (opening } \\
\text { boundaries) }\end{array}$ & $\begin{array}{c}\text { Local atmospheric pressure, computed according to the } \\
\text { altitude, ambient temperature. }\end{array}$ \\
\hline $\begin{array}{l}\text { Heat exchanging boundaries: closed } \\
\text { doors, windows walls, roofs and } \\
\text { floors }\end{array}$ & $\begin{array}{c}\text { Coefficients of heat transfer from the internal surface to } \\
\text { the outdoor environment: } U=\frac{1}{R_{s e}+\sum_{i=1}^{n} R_{i}}, \mathrm{Wm}^{-2} \mathrm{~K}^{-1} ; \\
\text { emissivity of the internal surfaces and ambient } \\
\text { temperature. }\end{array}$ \\
\hline
\end{tabular}

The variables $R_{s e}$ and $R_{i}$ in the equation in Table 1 are the thermal resistances of the external boundary layer and solid layers of the wall/roof/floor, $\mathrm{m}^{2} \mathrm{KW}^{-1}$. The overall coefficient of thermal transmittance of the windows and transparent doors $U$ can be used in the last boundary condition with a sufficient accuracy for the engineering purposes.

The mass fractions of the components of the gas fuel and its mass flow are computed at the common solution of the equations (1-5).

$$
\begin{aligned}
& \dot{Q}=\dot{m}_{s . m} L H V_{s . m}=\dot{V}_{g . f} L H V_{g . f}, \mathrm{~kW} \\
& \dot{V}_{\mathrm{CO}_{2}}=\dot{m}_{s . m} V_{C O_{2}}^{s . m}=\dot{V}_{g . f} V_{C O_{2}}^{g . f}, \mathrm{~m}^{3} \mathrm{~s}^{-1} \\
& \dot{V}_{\mathrm{H}_{2} \mathrm{O}}=\dot{m}_{s . m} V_{\mathrm{H}_{2} \mathrm{O}}^{s . m}=\dot{V}_{g \cdot f} V_{\mathrm{H}_{2} \mathrm{O}}^{g . f}, \mathrm{~m}^{3} \mathrm{~s}^{-1} \\
& \dot{V}_{\mathrm{SO}_{2}}=\dot{m}_{s . m} V_{S O_{2}}^{s . m}=\dot{V}_{g . f} V_{S O_{2}}^{g . f}, \mathrm{~m}^{3} \mathrm{~s}^{-1} \\
& C H_{4}+C O+\mathrm{H}_{2} S+H_{2} \mathrm{O}=100, \%
\end{aligned}
$$

where $\dot{Q}=$ heat flow, released at the combustion, $\mathrm{kW} ; \dot{m}_{s . m}=$ solid material mass, burned per unit time, $\mathrm{kgs}^{-1} ; \dot{V}_{g . f}=$ volumetric flow of the gas fuel at normal physical conditions, $\mathrm{m}^{3} \mathrm{~s}^{-1}$; $\dot{V}_{\mathrm{CO}_{2}}, \dot{V}_{\mathrm{H}_{2} \mathrm{O}}$ and $\dot{V}_{\mathrm{SO}_{2}}=$ volumetric flows of the components of the flue gases at normal physical conditions, $\mathrm{m}^{3} \mathrm{~s}^{-1} ; L H V_{\text {s.m }}=$ lower heating value of the burning solid material, $\mathrm{kJkg}^{-}$ ${ }^{3} ; V_{\mathrm{CO}_{2}}^{s . m}, V_{\mathrm{H}_{2} \mathrm{O}}^{\text {S.m }}$ and $V_{\mathrm{SO}_{2}}^{\text {s.m }}=$ specific volumes of the component of the flue gases at solid

\begin{tabular}{|c|c|}
\hline Solid material & Gas fuel mixture \\
\hline $\begin{array}{c}\text { Components (mass percentages): } \\
C, H, O, N, S, A \text { (ash), } W \text { (water content), \% }\end{array}$ & $\begin{array}{c}\text { Components (volumetric percentages): } \\
\mathrm{CH}_{4}, \mathrm{CO}, \mathrm{H}_{2} \mathrm{~S}, \mathrm{H}_{2} \mathrm{O}, \%\end{array}$ \\
\hline $\begin{array}{c}L H V_{s . m}=4.187(81 C+246 H-26(O-S)-6 W), \\
\mathrm{kJkg}^{-1}\end{array}$ & $\begin{array}{c}L H V_{g . f}=358.17 \mathrm{CH}_{4}+126.35 \mathrm{CO}+235.52 \mathrm{H}_{2} \mathrm{~S}, \\
\mathrm{kJm}^{-3}\end{array}$ \\
\hline$V_{C O_{2}}^{s . m}=0.01855 C, \mathrm{~m}^{3} \mathrm{~kg}^{-1}$ & $V_{C O_{2}}^{g . f}=0.01\left(\mathrm{CO}+\mathrm{CH}_{4}\right), \mathrm{m}^{3} \mathrm{~m}^{-3}$ \\
\hline$V_{H_{2} O}^{s . m}=0.112 H+0.0124 W, \mathrm{~m}^{3} \mathrm{~kg}^{-1}$ & $V_{H_{2} \mathrm{O}}^{g . f}=0.01\left(2 \mathrm{CH}_{4}+\mathrm{H}_{2} \mathrm{~S}+\mathrm{H}_{2} \mathrm{O}\right), \mathrm{m}^{3} \mathrm{~m}^{-3}$ \\
\hline$V_{S O_{2}}^{s . m}=0.000685 S, \mathrm{~m}^{3} \mathrm{~kg}^{-1}$ & $V_{S O_{2}}^{g . f}=0.01 H_{2} S, \mathrm{~m}^{3} \mathrm{~m}^{-3}$ \\
\hline
\end{tabular}
materials burning, $\mathrm{m}^{3} \mathrm{~kg}^{-1} ; L H V_{g . f}=$ lower heating value of the gas fuel, $\mathrm{kJm}^{-3} ; V_{\mathrm{CO}_{2}}^{f . g}, V_{\mathrm{H}_{2} \mathrm{O}}^{f . g}$ and $V_{\mathrm{SO}_{2}}^{f \cdot g}=$ specific volumes of the component of the flue gases at the combustion of fuel gas, $\mathrm{m}^{3} \mathrm{~m}^{-3}$ (Table 2).

Table 2. Lower heating values and flue gases components [11]

The parameters of the solid material burning process in Table 2 are computed at a known material composition. The unknown variables $\mathrm{CH}_{4}, \mathrm{CO}, \mathrm{H}_{2} \mathrm{~S}, \mathrm{H}_{2} \mathrm{O}$ and $\dot{V}_{g . f}$ can be obtained at the use of the expressions for the parameters of the gas mixture combustion (Table 2) in 
equations (1-5). Then the mass flow of the gas fuel $\dot{m}_{g . f}$ and the mass fractions $g$ of the components can be computed:

$$
\begin{gathered}
\dot{m}_{g . f}=\dot{m}_{C_{4}}+\dot{m}_{C O}+\dot{m}_{H_{2} S}+\dot{m}_{H_{2} O}=\frac{C H_{4}}{100} \dot{V}_{g . f} \rho_{C_{4}}+\frac{C O}{100} \dot{V}_{g . f} \rho_{C O}+\frac{H_{2} S}{100} \dot{V}_{g . f} \rho_{H_{2} S}+ \\
\quad \frac{H_{2} O}{100} \dot{V}_{g . f} \rho_{H_{2} O}, \mathrm{kgs}^{-1} \\
g_{C_{4}}=\frac{\dot{m}_{C H_{4}}}{\dot{m}_{g . f}}, \quad g_{C O}=\frac{\dot{m}_{C O}}{\dot{m}_{g . f}}, \quad g_{H_{2} S}=\frac{\dot{m}_{H_{2} S}}{\dot{m}_{g . f}}, \quad g_{H_{2} O}=\frac{\dot{m}_{H_{2} O}}{\dot{m}_{g . f}}
\end{gathered}
$$

where $\rho_{\mathrm{CH} 4}, \rho_{\mathrm{CO}}$ and $\rho_{\mathrm{H} 2 \mathrm{O}}$ are the densities of the correspondent gases at normal physical conditions.

\section{Numerical simulation of fires in a coffee storage hall}

The models above are solved numerically to simulate fire at a design stage of a coffee storage hall at a case of forced ventilation for evacuation of the smoke and the heat. The sizes of the building are width $=9.85 \mathrm{~m}$, length $=42.1 \mathrm{~m}$ and average height $=8.24 \mathrm{~m}$ (fig. 1). There are not windows on the facades. The higher long wall borders with another building. It is accepted as adiabatic boundary in the model. The coffee is stored in bags arranged near the floor. Three locations of burning are accepted on the floor in order to simulate 3 scenario of fire.

The finite volumes mesh is consisted of 1253580 elements, sharing 222856 nodes. The average size of the elements is $0.3 \mathrm{~m}$. The mesh is finer near the door, vents and fire locations. An air flow with volumetric flow of $27.5 \mathrm{~m}^{3} \mathrm{~s}^{-1}$ and ambient temperature of $30{ }^{\circ} \mathrm{C}$ is supplied through the open door on fig. 1 in order to dilute and evacuate the smoke through the vents. The air exchange rate per hour $(\mathrm{ARCH})$ is $29 \mathrm{~h}^{-1}$. It is obtained according to [12] at a thermal load of $840 \mathrm{kWhm}^{-2}$ at burning of coffee and an accepted height of the smokeless space lower than $50 \%$ of the average height of the hall. The vents on the roof are sized at the same conditions.

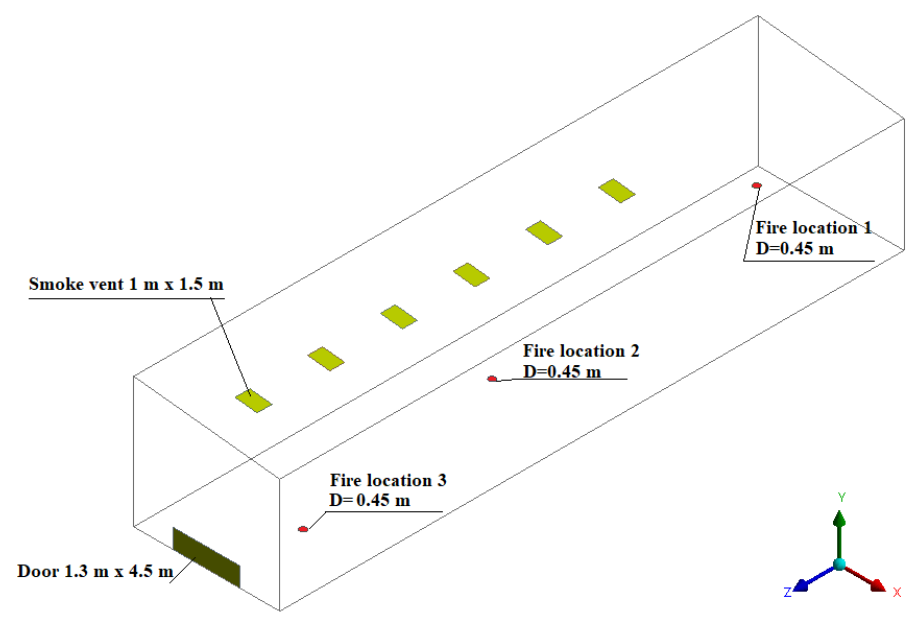

Fig. 1. Common view of the hall. 
The coffee composition is accepted according to [13], assuming that the spent coffee ground and the coffee have approximately the same compositions. The equilibrium moisture content of the coffee is accepted as $8 \%$. Details about the combustion process are given in Table 3. The computed flow of $\mathrm{SO}_{2}$, released at the combustion is relatively small and its concentration in the hall can be neglected at the high ARCH. So a zero concentration of $\mathrm{H}_{2} \mathrm{~S}$ is accepted and the volumetric flow $\dot{V}_{\mathrm{SO}_{2}}$ is added to $\dot{V}_{\mathrm{CO}_{2}}$ at the computing of the fuel gas composition. This step simplify the combustion modelling and enables using a two step model of combustion Methane Air WD2 NO PDF, available in CFX. The gas mixture of the model contains all possible component of the gases in the hall. The model also allows computing of nitrogen oxide if there are suitable conditions for its formation.

$k-\varepsilon$ model is used to simulate the turbulence effects. The buoyancy is modelled at density differences between the local and the reference density of the ambient air. The radiation heat transfer is neglected due to the negligible concentration and subsequent emissivity of the radiating gases $\left(\mathrm{CO}_{2}, \mathrm{H}_{2} \mathrm{O}\right.$ and $\left.\mathrm{CH}_{4}\right)$ in the hall space.

Table 3. Components of the fuels, lower heating values and flows

\begin{tabular}{|c|c|}
\hline Coffee & Gas fuel mixture \\
\hline $\begin{array}{c}\text { Components (mass percentages): } \\
C=39.43 \%, H=7.89 \%, S=1.47 \% ; O=41.63 \% \text {, } \\
N=1.28 \%, A=0.30 \%, W=8.00 \%\end{array}$ & $\begin{array}{c}\text { Components (volumetric percentages): } \\
\mathrm{CH}_{4}=30 \%, \mathrm{CO}=40 \%, \mathrm{H}_{2} \mathrm{~S}=0 \%, \mathrm{H}_{2} \mathrm{O}=30 \%\end{array}$ \\
\hline \multicolumn{2}{|c|}{$\dot{Q}=258 \mathrm{~kW}$} \\
\hline$L H V_{s . m}=16916 \mathrm{kJkg}^{-1}$ & $L H V_{g . f}=15799 \mathrm{kJm}^{-3}$ \\
\hline \multirow[t]{2}{*}{$\begin{array}{c}\dot{m}_{s . m}=0.0167 \mathrm{kgs}^{-1} \\
\text { (corresponding to } 1 \mathrm{~kg} \text { coffee burning per } \\
\text { minute) }\end{array}$} & $\dot{V}_{g . f}=0.0178 \mathrm{~m}^{3} \mathrm{~s}^{-1} ; \quad \dot{m}_{g . f}=0.0170 \mathrm{kgs}^{-1}$ \\
\hline & $g_{\mathrm{CH}_{4}}=0.224 ; g_{C O}=0.523 ; g_{\mathrm{H}_{2} \mathrm{O}}=0.252$ \\
\hline $\begin{array}{c}\dot{V}_{\mathrm{CO}_{2}}=0.024 \mathrm{~m}^{3} \mathrm{~s}^{-1} ; \quad \dot{V}_{\mathrm{H}_{2} \mathrm{O}}=0.013 \mathrm{~m}^{3} \mathrm{~s}^{-1} \\
\dot{V}_{\mathrm{SO}_{2}}=0.0002 \mathrm{~m}^{3} \mathrm{~s}^{-1}\end{array}$ & $\dot{V}_{\mathrm{CO}_{2}}=0.025 \mathrm{~m}^{3} \mathrm{~s}^{-1} ; \quad \dot{V}_{\mathrm{H}_{2} \mathrm{O}}=0.013 \mathrm{~m}^{3} \mathrm{~s}^{-1}$ \\
\hline
\end{tabular}

Table 4. Boundary conditions for numerical simulation of fires in a coffee storage hall

\begin{tabular}{|c|c|}
\hline Boundary & Variable \\
\hline Fire locations (inlets) & $\begin{array}{c}\dot{m}_{g . f}=0.0170 \mathrm{kgs}^{-1} ; \\
g_{\mathrm{CH}_{4}}=0.224 ; g_{C O}=0.523 ; g_{H_{2} O}=0.252 ; \\
t_{\text {gas }}=20^{\circ} \mathrm{C}\end{array}$ \\
\hline Opened door (inlet) & $\begin{array}{l}\text { Velocity, normal to the boundary } V_{n}=4.3 \mathrm{~m} / \mathrm{s} \text { (at the } \\
\text { supplied air flow through the door); } \\
\text { ambient temperature of } 30^{\circ} \mathrm{C} \text {. }\end{array}$ \\
\hline $\begin{array}{c}\text { Smoke vents on the roofs (opening } \\
\text { boundaries) }\end{array}$ & Average gauge pressure $0 \mathrm{~Pa}$; ambient temperature of $30^{\circ} \mathrm{C}$. \\
\hline $\begin{array}{l}\text { Heat exchanging boundaries: walls, } \\
\text { roof and floor }\end{array}$ & $\begin{array}{l}\text { Heat exchange at } U=0.3 \mathrm{Wm}^{-2} \mathrm{~K}^{-1} \text { for all building } \\
\text { envelopes (floor, roof, floor); } \\
\text { walls and roof: ambient temperature of } 30^{\circ} \mathrm{C} \text {; } \\
\text { floor: ambient temperature of } 10^{\circ} \mathrm{C}\end{array}$ \\
\hline $\begin{array}{l}\text { Wall, bordering with an adjacent } \\
\text { building }\end{array}$ & Adiabatic boundary \\
\hline
\end{tabular}

The models were solved numerically at the conditions above for the chosen fire locations and are validated by mass and energy balances on the base of the obtained results. The differences between the mass flows, entering and leaving the hall are less than $1 \%$. The 
differences between the input heat flow (released at the combustion) and sum output heat flows, including the thermal loses through the building envelopes and the heat flow of the exhaust gas mixture, are below $2 \%$. So the obtained results can be accepted as reliable in order to estimate the processes at the modelled variants.

The computed temperatures, mass fractions of $\mathrm{CO}_{2}$ and fluid flow fields are visualised on the figures below. The space orientations of the building are chosen in order to ensure good view of the fires.

The established concentration of $\mathrm{CO}$ and $\mathrm{CH}_{4}$ at the openings are negligible at all modelled scenarios. Therefore, the combustion processes proceeded completely. The $\mathrm{CO}_{2}$ distribution is similar to the temperature one (fig. 2 and 3).

Higher thermal loads on the building walls are established at the fire location 1 (fig. 2). In this case, the main airflow distorts the flame and the mixing of the ventilation air and the flue gases is straitened (fig. 5). The temperature on the vertical wall near the fire reaches 190 ${ }^{\circ} \mathrm{C}$. The temperature gradients on the hot zones are relatively high. That will cause thermal stresses and damages if the wall is not fire resistant.

At the other fire locations, the fresh airflows dilute well the flue gases (fig. 7 and 9) and the concentration of $\mathrm{CO}_{2}$ is negligible in the overall internal space. The temperature fields on the building envelopes are more even and the temperatures and their gradients on the internal wall surfaces are smaller (fig. 6 and 8).

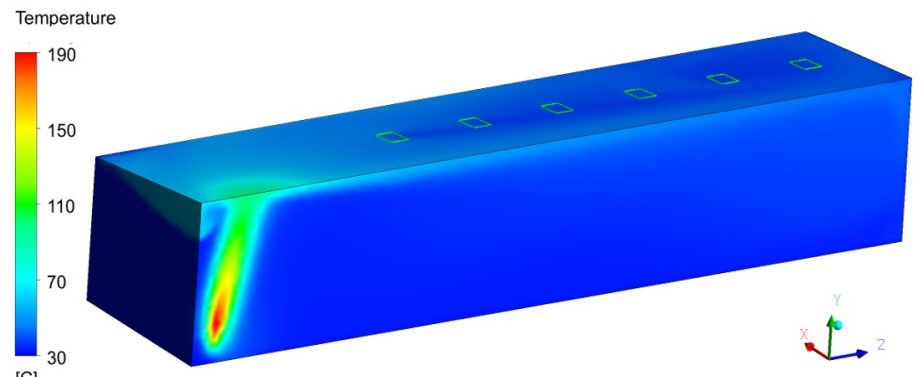

[C]

Fig. 2. Temperature field of the internal surfaces of the walls at fire location 1 .

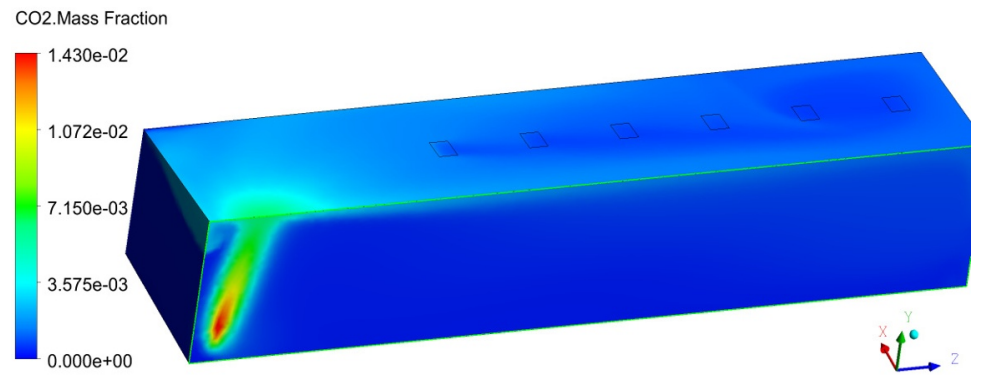

Fig. 3. Mass fraction of $\mathrm{CO}_{2}$ near the internal surfaces of the walls at fire location 1. 


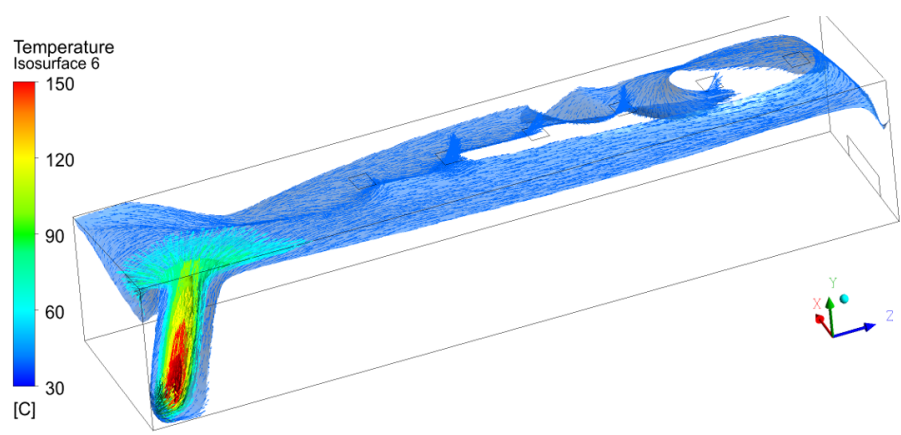

Fig. 4. Isothermal surfaces $\left(40,60,80,100,120\right.$ and $\left.150^{\circ} \mathrm{C}\right)$ and vectors, belonging on them at fire location 1.

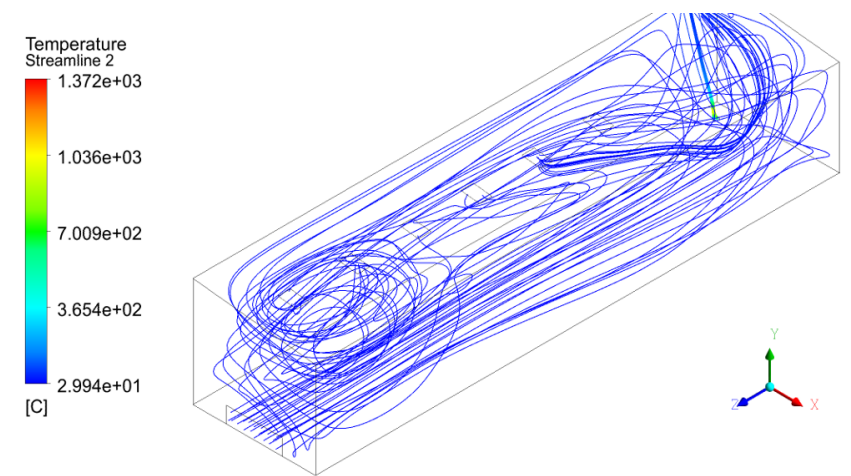

Fig. 5. Streamlines at fire location 1.

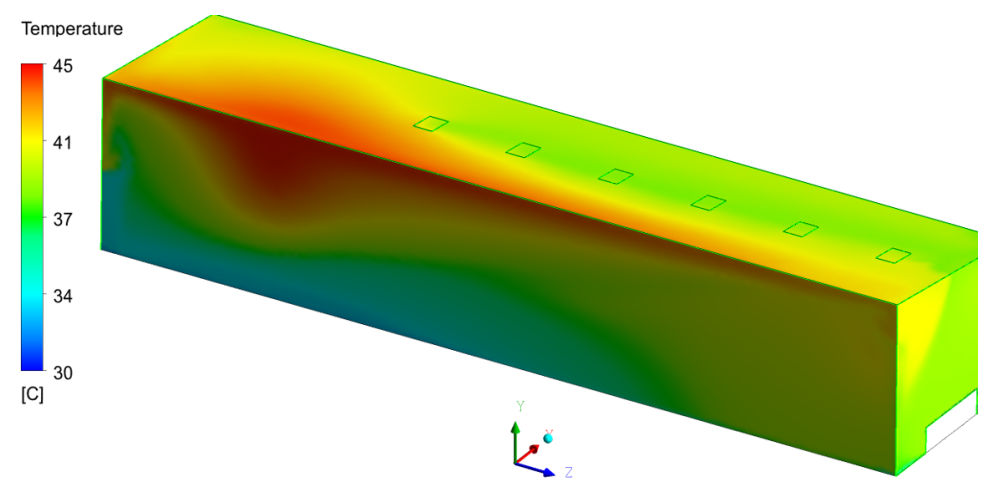

Fig. 6. Temperature field of the internal surfaces of the walls at fire location 2 . 


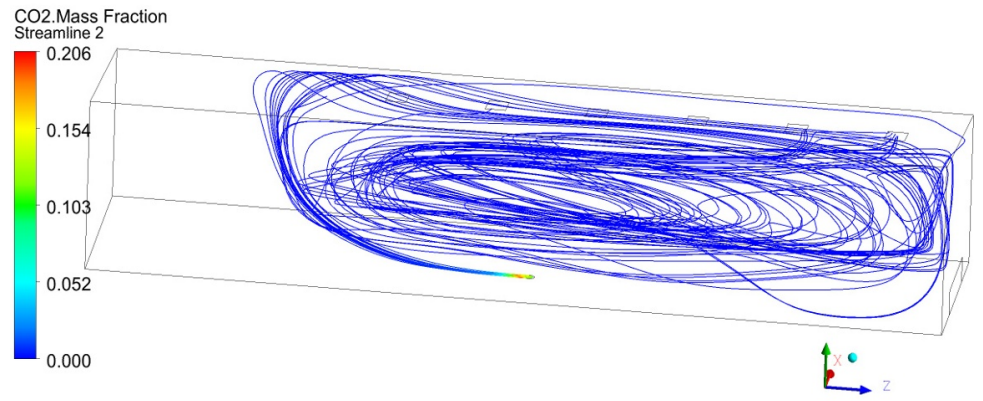

Fig. 7. Streamlines, starting from fire location 2, coloured by the mass fraction of $\mathrm{CO} 2$.

In the all analyzed cases, the smoke is collected and retained due to the buoyancy in the zones above the smoke vents. Therefore, the chosen positions of the smoke openings are not suitable -they must be located in the highest parts of the roof and have to be evenly distributed along the length of the building.

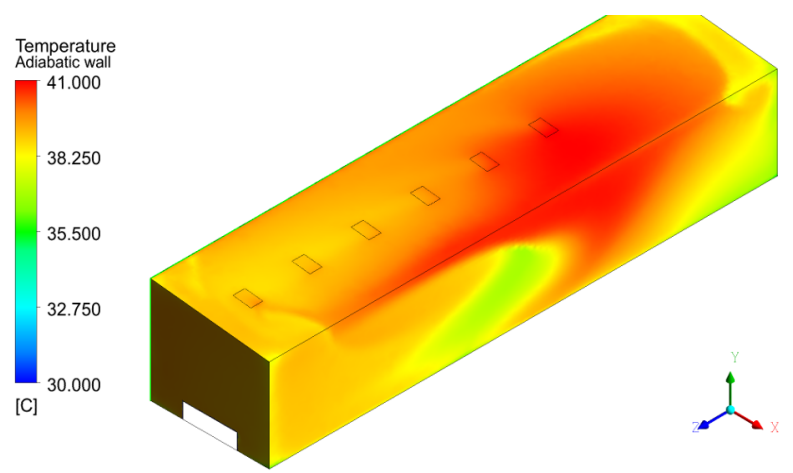

Fig. 8. Temperature field of the internal surfaces of the walls at fire location 3 .

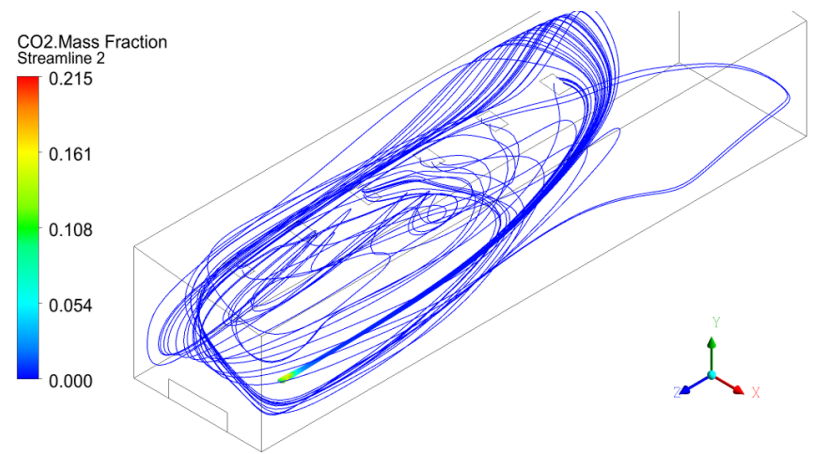

Fig. 9. Streamlines, starting from fire location 3, coloured by the mass fraction of $\mathrm{CO} 2$. 


\section{Conclusions}

The proposed concepts for modeling and numerical simulations allow analyses of different fire scenarios in buildings, changing the fire locations, solid material quantity and compositions, and organization of forced ventilations. For proper analyses, the simulations must be done at a pre-estimated maximal burning rate of the materials.

The results allow assessments of the efficiency of the vents position and ventilation mode, and determinations of suitable arrangements of the combustible solids in the storage halls. The thermal load analyses of the building envelope at different fire scenarios enable proper choice of the materials for the internal layers of the walls.

This study has been financially supported by the project BG05M2OP001-1.001-0008: National Centre of Mechatronics and Clean Technologies, funded by Operational Programme for Science and Education for Smart Growth at EU Funds.

\section{References}

1. V. Dréan, B. Girardin, E. Guillaume and T. Fateh, Fire and Materials 47, 7, 839-856 (2019)

2. K.B. Mcgrattan, Fire Safety Science, 8, 53-68 (2005)

3. A.C.Y. Yuen, G.H. Yeoh, R.K.K. Yuen and T. Chen, Procedia Engineering, 52, 3-12 (2013)

4. Z. Vass, A.B. Şimon-Marinică and S. Stănilă, MATEC Web of Conferences, EDP Sciences, 305, 00024, (2020)

5. W.K.Chow, C. L. Chow, and S. S. Li, Modelling and Simulation in Engineering, 2011, Article ID 781252 (2011)

6. K. Prasad, R. Kramer, N. Marsh, M. Nyden, T. Ohlemiller and M. Zammarano, Fire research division, BFRL, NIST annual fire conference (2009)

7. A. Rahmani and M. Salem, Electron J Gen Med. 2020, 17 (3), em200 (2020)

8. K. McGrattan, S. Hostikka, R. McDermott, J. Floyd, C. Weinschenk, and K. Overholt, Fire dynamics simulator - Technical reference guide, Volume 1: Mathematical model, NIST special publication, 1018 (1), (2013)

9. ANSYS Release 16 - C SAS IP, Inc. (2016)

10. S. Deliev, V. Iliev, M. Hristova, N. Penkova, Proceedings of XXIII scientific conference with international participation FPEPM 2018, 138-144 (2018)

11. I. Kassabov and L. Zashcova, Technical thermodynamics and thermal techniques, (in Bulgarian), Martilen (1991)

12. Bulgarian regulation No Ih $1971 / 2009$ on building/technical regulations and fire safety standards (2018)

13. G.A. Kristanto and H. Wijaya, IOP Conference Series: Earth and Environmental Science, 195 (1), 012056 (2018) 